\title{
Série Temática - Terminalidade da Vida e Cuidados de Final de Vida na Unidade de Terapia Intensiva
}

\author{
Thematic Series - End-of-Life Care and The Terminally \\ ill Patient at the Intensive Care Unit
}

Márcio Soares, $P h D^{1}$, Renato G. G. Terzi, $P h D^{2}$, Jefferson P. Piva, $P h D^{3}$.

As questões relacionadas à terminalidade da vida e a limitação de tratamentos de suporte em pacientes com doenças incuráveis e terminais ainda são considerados como tabu no Brasil e a sua discussão mais aprofundada foi negligenciada durante anos até bem pouco tempo. Assim como em diversos países, uma parcela significativa das mortes intra-hospitalares ocorre nas unidades de terapia intensiva (UTI). A Medicina Intensiva é uma especialidade relativamente jovem, tendo ocorrido no Brasil um aumento considerável no número de UTI nos últimos anos. Os intensivistas, de modo geral, têm sido ávidos na incorporação de inovações tecnológicas. Paralelamente, observa-se um crescente questionamento quanto a eficácia e prováveis benefícios desses tratamentos quando utilizados de modo inapropriado ou contra a vontade dos pacientes. Assim, as questões relacionadas a terminalidade da vida estão na ordem do dia, alavancadas pela recente publicação da Resolução n 1.805/06 do Conselho Federal de Medicina, que ampliou a discussão, tanto na

1. Médico do Centro de Tratamento Intensivo, Instituto Nacional de Câncer, Rio de Janeiro; Mestre e Doutor em Clínica Médica pela UFRJ, Título de Especialista em Medicina Intensiva pela AMIB 2. Professor Titular de Cirurgia, UNICAMP, Campinas, SP; Doutor em Cirurgia pela UNICAMP; Pós-Doutor pela Universidade de Harvard, EUA; Título de Especialista em Medicina Intensiva pela AMIB 3. Professor Adjunto dos Departamentos de Pediatria da PUCRS e da UFRGS, Porto Alegre, RS; Chefe associado da UTIP do Hospital São Lucas - PUCRS, Porto Alegre, RS; Secretário da World Federation of Pediatric Intensive and Critical Care Societies (WFPICCS); Doutor em Pediatria pela UFRGS

Endereço para correspondência

Dr. Márcio Soares

Núcleo de Pesquisa Clínica em Medicina Intensiva

Instituto Nacional de Câncer - INCA

Centro de Tratamento Intensivo - $10^{\circ}$ Andar

Praça Cruz Vermelha, 23

20230-130 Rio de Janeiro, RJ

Fone: (21) 2506-6120; Fax: (21) 2294-8620

E-mail: marciosoaresms@yahoo.com.br, marciosoaresms@globo.com

(C)Associação de Medicina Intensiva Brasileira, 2007 comunidade médica como na sociedade civil ${ }^{1,2}$. Como em qualquer outro lugar, decisões sobre a propriedade da instituição ou da suspensão dos cuidados intensivos sempre ocorreram no Brasil. Entretanto, alguns médicos em nosso meio têm receios de ordem legal na limitação de cuidados vitais em pacientes com doenças terminais. Este receio legal (mesmo que discutível), inibe uma maior participação da família neste processo decisório, impedindo assim maior discussão e divulgação de informações a respeito destas práticas. Em três estudos com pacientes adultos internados em UTI, a freqüência de decisões para a limitação de suporte de vida (LSV), foram tomadas em $11 \%$ a $36,3 \%$ dos pacientes que faleceram ${ }^{3-5}$. Números semelhantes foram também relatados em pacientes pediátricos, nos quais as decisões foram tomadas em $18,1 \%$ a $36, \%$ das crianças ${ }^{6,7}$. Estes números são menores do que os descritos em países europeus e da América do Norte, mas são relativamente semelhantes aos observados na Argentina, por exemplo ${ }^{8-10}$.

Muitas são as barreiras e limitações para a implementação de cuidados de final de vida no Brasil. Existe ainda uma grande confusão, não apenas na comunidade leiga, mas também por muitos profissionais de saúde, sobre definições de termos como "eutanásia", "ortotanásia", "distanásia", "cuidados paliativos" e "cuidados de final de vida", dentre outros. Além disso, a formação dos profissionais ainda é centrada no cuidado curativo. Nos currículos da maioria dos cursos de graduação e de especialização não há qualquer referência aos cuidados paliativos e às questões ligadas a terminalidade da vida.

Neste contexto, o momento é extremante oportuno para o aprofundamento das discussões sobre esta temática, assim como nos prepararmos para incluir cada vez mais os pacientes e familiares nesta discussão. A RBTI publicará a partir deste fascículo uma série temática sobre os principais aspectos relacionados à terminalidade da vida e práticas de cuidados de fim 
de vida no Brasil. Esperamos que esta série seja uma ferramenta útil para ajudar a melhorar a qualidade de atendimento aos pacientes com doenças em fase terminal em nosso País.

\section{REFERÊNCIAS}

01. Terzi RGG, Silveira OC - Suporte Avançado de Vida: Até Quando? em: Rocha e Silva M - Choque - Série Clínicas Brasileiras de Medicina Intensiva. Editora Atheneu, São Paulo, 1986.

02. Terzi RGG e Silveira OC - Futilidade terapêutica. Âmbito Hospitalar 2003;159:13-17.

03. Soares M, Salluh JI, Ferreira CG et al - Impact of two different comorbidity measures on the 6-month mortality of critically ill cancer patients. Intensive Care Med, 2005;31:408-415.
04. Vieira JM Jr, Castro I, Curvello-Neto A et al - Effect of acute kidney injury on weaning from mechanical ventilation in critically ill patients. Crit Care Med, 2007;35:184-191.

05. Moritz RD, Pamplona F - Avaliação da recusa ou suspensão de tratamentos considerados fúteis ou inúteis em UTI. RBTI, 2003;15:40-44.

06. Kipper DJ, Piva JP, Garcia PC et al - Evolution of the medical practices and modes of death on pediatric intensive care units in southern Brazil. Pediatr Crit Care Med, 2005;6:258-263.

07. Lago PM, Piva J, Kipper D et al - Life support limitation at three pediatric intensive care units in southern Brazil. J Pediatr, 2005; 81:111-117.

08. Sprung CL, Cohen SL, Sjokvist P et al - End-of-life practices in European intensive care units: the Ethicus Study. JAMA, 2003;290:790-797.

09. Prendergast TJ, Claessens MT, Luce JM - A national survey of end-of-life care for critically ill patients. Am J Respir Crit Care Med, 1998;158:1163-1167.

10. Althabe M, Cardigni G, Vassallo JC et al - Dying in the intensive care unit: collaborative multicenter study about forgoing life-sustaining treatment in Argentine pediatric intensive care units. Pediatr Crit Care Med, 2003;4:164-169 